\title{
El cuerpo como territorio
}

\section{Di Bella, Daniela V. [ver currículum del autor, docente de la Facultad de Diseño y Comunicación]}

Resumen:

Asistimos a una emergencia del

cuerpo en la sociedad

contemporánea, que puede asumirse

como un espacio de

reconceptualización. La

posmodernidad viene reescribiendo

una iconografía y estética particular

del cuerpo en torno a la

imagenmercancía, que impacta sobre las distintas variables de lo social, ficcional, performá- tico y fashionable, que traducen la construcción de la identidad de lo individual y de lo colectivo. El diseño y en particular de indumentaria han decodificado y creado sobre la relación que guardan los productos con el cuerpo, siendo necesario también reflexionar sobre las distintas visiones de esa relación compleja y no siempre sostenible. El diseño en la sociedad posindustrial tiene nuevos capítulos interdisciplinarios por resolver, que signan el presente y el futuro de la disciplina.

Palabras clave:

cuerpo - posmodernidad - iconografía - estética - identidad -imagen - reconceptualización - complejidad sostenible - interdisciplina.

Desde la visión fenomenológica Merleau Ponty define que el "yo" reside en el cuerpo, y que este no es el resultado de las causalidades que lo determinan, y en consecuencia no puede ser entendido únicamente como un objeto de la biología, la psicología, la sociología y la ciencia misma. (Merleau-Ponty, 1985, p. 8) Su concepción del cuerpo se apoya sobre "la experiencia del mundo" y la construcción del mundo vívido, donde el cuerpo a través de la percepción establece juicios acerca de la realidad en una relación singular "Más nuestro cuerpo no tiene el poder de hacernos ver aquello que no existe; solo puede hacernos creer que lo vemos" (Merleau-Ponty, 1985, pp. 49-55) El mundo vívido es la propia historia perceptiva del mundo objetivo, donde tiempo y espacio cobrarían sentido como coordenadas de la existencia: 
Mi presente, que es mi punto de vista acerca del tiempo, se convierte en un momento del tiempo entre todos los demás, mi duración en un reflejo o un aspecto abstracto del tiempo universal, como mi cuerpo en un modo del espacio objetivo. (Merleau-Ponty, 1985, p. 90)

Complementando los conceptos de Merleau Ponty, y desde la antropología social, Le Bretón define que la "existencia del hombre es corporal", lo que establece un vínculo inexorable con su identidad (Le Breton, 2002, p. 7) donde el cuerpo visto desde la perspectiva de nuestra sociedad, es una construcción simbólica de la cultura y las sociedades de Occidente. El cuerpo entonces posibilita constituirse sujeto, las representaciones significantes de un estado social, la definición de una visión del mundo, la consecuente definición de la persona y la formación del yo. (Le Breton, 2002, pp. 13-14) Actualmente el cuerpo es objeto de investigación no solo de la antropología, la biología, las ciencias médicas y la historia, sino también de los estudios culturales, la literatura, la fotografía, el cine, la danza, la escenificación entre muchas otras disciplinas que exploran la construcción de la imagen social, cultural y psicológica del cuerpo. La corporeidad conceptualmente espacial y temporal, permitiría que el cuerpo se comporte como un contenedor, como un lugar. Esta definición pertenece a Hans Belting, quién explica, que si el cuerpo es un lugar en el mundo, también "es un lugar en el que se crean y se conocen (reconocen) imágenes; y, las que quedan presas de nuestro recuerdo corporal están ligadas a una experiencia de vida en el tiempo y en el espacio". Estas imágenes impactan en nuestra percepción cargadas de un sentido técnico propio de los medios de comunicación y de la información, que revelan:

La forma de recuerdo que las imágenes adquieren en nosotros donde la experiencia medial con imágenes es un ejercicio cultural. Nuestro cuerpo natural representa también un cuerpo colectivo y es también en este sentido un lugar de las imágenes, a partir de las cuales existen las culturas. Solo que en la actualidad el individuo ha dejado de estar sujeto a una cultura, que antes le imponía un contexto fijo y también las fronteras de su margen de acción personal. (Belting, 2007, pp. 72-76)

Desde la perspectiva de los media digitales, desde 1990 se ha investigado de manera central la vinculación entre las percepciones y la forma de recepción de aquellos, sobre todo en los que interviene la realidad virtual, y estos otorgan una preeminencia al uso del cuerpo, desplazando las concepciones visuales tradicionales, e integrando a la percepción visual con lo táctil, la sinestesia y las dimensiones propioceptivas en la construcción mediatizada de los objetos. Laura Marks una estudiosa del cine experimental de contextos interculturales atravesados por visiones de distintas procedencias geográficas y contextuales, analiza lo que define como la piel del film, y reflexiona sobre la construcción de estas imágenes del cuerpo, estableciendo que son parte de una endocultura propia dentro de cada cultura específica, lo que implica un entrenamiento selectivo de los sentidos, o previamente orientados por procesos de pertenencia e identidad que construyen una "configuración cultural sensorial específica" que nos aleja de la neutralidad sensorial. Basándose en el pensamiento de Henri Bergson sostiene que el cuerpo posee una relación visceral y mimética con el mundo a través de las construcciones de la memoria emocional y cerebral, y que esta memoria es multisensorial. Estas definiciones de Marks conducen hacia las nociones de lo háptico donde los ojos asumen las formas del sentido táctil, y si bien la imagen háptica es menos completa aporta la construcción de una subjetividad dinámica entre espectador y la imagen (Fisher, 1997 y Marks, 2002, p. 163 en Di Bella, 2015). Belting recurre a Marc Auge, para puntualizar que en los sueños o los rituales, las imágenes pueden dominar o poseer al cuerpo, que lo "ocupan, abandonan o regresan" como si el cuerpo se constituyera en escenario de las imágenes desplegadas por su doble identitario. (Belting, 2007, pp. 72-76) En este mundo cultural y social el cuerpo se aparece como un cuerpo vestido, donde la desnudez en casi todas las situaciones sociales puede resultar inapropiada, aun en aquellas donde está permitida una cuota de 
exhibición personal, y los usos de las prendas de vestir se asumen como socializadoras en cuanto reportan un estado de comprensión y aceptación de las convenciones culturales: "la ubicua naturaleza del vestido parece apuntar al hecho de que la ropa o los adornos son uno de los medios mediante los cuales los cuerpos se vuelven sociales y adquieren sentido e identidad". De este modo el encuentro de la esfera privada del cuerpo con la esfera social o pública se realiza a través de la experiencia del vestir (Entwistle, 2002, pp. 11-12); se constituye en:

Conformador de la subjetividad de las personas como seres individuales y sociales (...) la imagen corporal y el cuerpo individual y social son fundamentales en la construcción de la propia identidad y pertenencia a los diferentes grupos (...) el sujeto está constituido por una entidad individual cuyas fronteras se sitúan en la superficie del cuerpo y muchas de las identidades corporales ideales suelen venir definidas de antemano, envasadas y dispuestas para el público desde las industrias de consumo, belleza y publicidad. (Falk, 1994 en Esteban, 2004, p. 67)

Estas identidades corporales ideales han sido estudiadas y definidas desde el estructuralismo y postestructuralismo, como mecanismos de control social, de este modo el cuerpo es orientado por una serie de políticas del cuerpo (biopolíticas) que lo intervienen en la conquista de su docilidad, producción y regulación:

El control de la sociedad sobre los individuos no se opera simplemente por la conciencia o por la ideología sino que se ejerce en el cuerpo, con el cuerpo. Para la sociedad capitalista lo importante era lo biológico, lo somático, lo corporal antes que nada. (Foucault, 1996, p. 87. Foucault, 1980-2000)

En palabras de Giddens:

El cuerpo se convierte en el punto focal del poder y ese poder, en vez de intentar marcarlo extemamente, como ocurría en las épocas premodernas, lo somete a una disciplina intema de autocontrol. Según el retrato trazado por Foucault, los mecanismos disciplinarios producen -cuerpos dóciles-. (Giddens, 1997, p. 78)

Una de las biopolíticas más encarnadas de Occidente de acción de lo global sobre lo local, es la descripta por George Ritzer como la macdonalización de la sociedad donde los principios:

Que rigen el funcionamiento de los restaurantes de comida rápida han ido dominando un número cada vez más amplio de aspectos de la sociedad norteamericana, así como de la del resto del mundo (...) no sólo afecta al negocio de los restaurantes, sino también a la educación, el trabajo, los viajes, el ocio, las dietas, la política, la familia, y prácticamente a todos los demás aspectos de la vida. (Ritzer, 1996, p. 14)

Giddens completa la interpretación de Foucault sobre el vínculo disciplina y cuerpo, explicando que "en esencia, el cuerpo unido al poder es igual a actuación" y agrega "el control rutinario del cuerpo es parte integrante de la naturaleza misma tanto de la actuación como del ser aceptable (fiable) para los otros como competente". De esta manera establece dos variables simultáneas a partir del control reglado del cuerpo, una el "mantenimiento de una biografía de la identidad del yo", y la segunda, la exposición a los demás a través de la corporalidad (distinción del yo del mi) íntimamente relacionado al vínculo social, vulnerable a las reacciones de los demás y expuesto al riesgo de su integridad. (Giddens, 1997, p. 78, p. 89 y p. 163) Desde la idea del cuerpo vestido, Johanne Enwistle, basada en los análisis de Thomas Csordas y Nick Crossley, orienta el análisis en la 
integración de dos tradiciones de pensamiento, una sustentada sobre la idea del cuerpo determinado por las variables sociales del contexto cultural e histórico (estructuralista y postestructuralista), y una segunda que incorpora al vestido como una experiencia corpórea (fenomenológica), sugiriendo el estudio de una sociología del cuerpo vestido que da paso a los estudios de Pierre Bourdieu y Edwin Goffman. En palabras de Salzman, el vestido:

Es la forma más inmediata que se habita, y regula los modos de vinculación entre el cuerpo y el entorno, deviene en textualidad y significación para el espacio público: En su calidad de objeto social, el vestido se convierte entonces en signo de los atributos del sujeto. (Salzman, 2004, pp. 9-12)

Entwistle sugiere que el estudio de una sociología del cuerpo vestido podría integrar las miradas del estructuralismo, el postestructuralismo y la fenomenología. Estos aspectos dan cuenta de la relación compleja y dinámica que establecen el cuerpo y el vestido (circuitos de la moda y la cultura de Occidente), donde el vestir puede ser entendido como una práctica corporal en contexto condicionada por la presentación dentro de una situación social. (Entwistle, 2002, pp. 16-18) Peeters y Charlier, definen que la sociedad contemporánea se fue cargando de una nueva relación con los objetos en una época en la "que es posible otra relación con el mundo material, objetual, ya no sobre el modo de instrumentación o de alienación, sino sobre el modo de la frecuentación, del contacto o aún de la experiencia afectivo-corporal, incluso del juego..." (Peeters y Charlier, 1999 en Di Bella, 2007, pp. 39-75). Bajo estas condiciones, Jean Baudrillard define el cuerpo como imagenmercancía, respondiendo a una economía política del signo, donde el individuo deviene en objeto, e ingresa en la lógica del consumo en un proceso económico de rentabilidad. El sujeto inmerso en las actuales formas de producción y consumo, posee una doble representación de su cuerpo, bajo la forma de capital (inversión) y como signo social (fetiche) (Baudrillard, 2009, pp. 214-244). El cuerpo se aparece un objeto más del consumo, dando paso a una variada serie de acciones centradas en la figura de Narciso, que en los contextos de la subjetividad contemporánea ha efectuado un pasaje de la concepción del sujeto clásico, a la del sujeto operativo, un sujeto que no sabe bien por qué hace las cosas, un sujeto con vacío simbólico. El sujeto clásico es el individuo que subyace en su fuero interno, el que obedece visiblemente la ley pero internamente se encuentra en permanente contradicción, rebeldía y conflicto. A partir de los estados de contradicción replegados y latentes de los sujetos de la modernidad, y parte de un contexto económico y político de fuertes injusticias impulsadas por el capitalismo, que no condujeron a una sociedad más justa y humana, se operaron una serie de fuertes cambios, reivindicaciones y luchas sociales, que significaron la crisis del sujeto clásico y la consecuente emergencia del sujeto operativo (Pérez Soto, 2008. En Di Bella, 2013, pp. 127- 139). El sujeto operativo entiende que su cuerpo puede ser transformado en un proyecto personal (Gimlin, 2006) alineado con lo bello e ideal, eróticamente cultivado, a la orden de las nuevas exigencias del sentirse bien, dietas y regímenes alimenticios, autocuidados varios, cirugías estéticas, entre otras, asociadas con ideas de felicidad, status y realización personal. La belleza imaginada, no está necesariamente unida a la salud, se relaciona con un ideal ausente, que promueve una necesidad de modificación corporal, que dados los avances médicos y tecnológicos, tiene un potencial ilimitado para el cambio, y lo ha vuelto una mercancía actualizable o commodity (Gimlin, 2000, p. 81). Zizek lo define de esta manera:

Un verdadero materialismo asume gozosamente la "desaparición de la materia", el hecho de que sólo hay vacío (...). Lejos de servir como referencia última, el cuerpo pierde su densidad misteriosa e impenetrable y se convierte en algo que se puede manejar tecnológicamente, en algo que podemos engendrar y transformar mediante la intervención (...). (Zizek, 2006, p. 42) 
El proyecto personal del cuerpo tiende a reivindicar aspectos relacionados mayormente con la diferencia, y según esta premisa los tatuajes y las modificaciones corporales a partir de los piercings, incisiones y otras aplicaciones que marcan el cuerpo como signo, han dejado las significaciones culturales de tipo ritual y religiosa, para ser en la contemporaneidad maneras en las que se expresa el erotismo, la identidad, la provocación, la pertenencia y/o la exclusión de lo normativo (Foos, 2012). Jannson califica a la intervención del propio cuerpo, una cuestión de determinismo posmoderno, lo que Csordas define como "paradigma del texto, en cuyo marco el cuerpo es concebido como una entidad producida discursivamente, y pasivamente sometida a los efectos del poder del discurso", el -determinismo posmoderno- sería el equivalente a la aplicación de un -determinismo discursivo- sobre el cuerpo, cuyos contenidos son los textos del imaginario mediático. (Jannson, 2002 y Csordas, 1994 en Córdoba, 2010, p. 38) Anthony Giddens se dirige hacia el sustrato del proyecto personal del cuerpo, y define que en este interés hay un afán "mucho más profundo por construir y controlar el cuerpo" vinculando de manera deliberada al "desarrollo corporal con el estilo de vida". (...) "Tanto la planificación de la vida como la adopción de opciones de estilo de vida se integran -en principio- en los regímenes corporales" (Giddens, 1997, p. 16 y p. 132). Y continúa:

El cultivo del cuerpo por la observación de una dieta, una forma de vestir, la apariencia del rostro y otros factores es una cualidad común de las actividades del estilo de vida en la vida social contemporánea (...) La planificación de la vida respecto al cuerpo no es, por tanto, necesariamente narcisista, sino una parte normal de los entornos sociales postradicionales (Giddens, 1997, p. 225)

La superación de Narciso en la construcción del concepto del cuerpo posmoderno, lo ha puesto en el centro de una reconceptualización que lo vuelve emergente en relación con la sociedad y la naturaleza. El neurobiólogo Francisco Varela explica que recién en estas tres últimas décadas, el campo de la ciencia está aceptando visiones más amplias de interpretación de la realidad debido a que históricamente Occidente ha venido realizando una apropiación e interpretación condicionada del campo de la realidad, como herencia del cisma entre los postulados de Descartes (reduccionismo) y los dogmas teológicos de la Iglesia, o la división entre el cuerpo y el alma, dualismo que ha signado siglos de construcciones disociadas del conocimiento teórico, filosófico, ético y moral (Asencio, 2008. En Di Bella, 2013, pp. 127-139). Así,

Si al principio se creyó que (el cuerpo) era el lugar del alma y, más tarde, el centro de necesidades oscuras y perversas, el cuerpo es ahora plenamente susceptible de ser trabajado por las influencias de la modernidad reciente. A consecuencia de estos procesos se han alterado sus límites. (Giddens, 1997, p. 275)

La noción de riesgo e integridad del cuerpo refiere también cuestiones globales de cómo ejerceremos las actuales y futuras condiciones de la supervivencia humana, en cuanto planos de decisión política sobre la vida:

La política de la vida es política de estilo de vida (...) refiere a cuestiones políticas que derivan de procesos de realización del yo en circunstancias postradicionales, donde las influencias universalizadoras se introducen profundamente en el proyecto reflejo del yo y a su vez, estos procesos de realización del yo influyen en estrategias globales. (Giddens, 1997, p. 271)

También hace referencia a la noción compleja de propiedad del cuerpo y al campo de decisión política que opera sobre las condiciones físicas y biológicas del cuerpo, la manifestación de la sexualidad, la continuidad de la 
especie, y la reproducción, entre otras de índole esencial como el derecho sobre el cuerpo y la noción de persona:

El cuerpo, al igual que el yo, pasa a ser un lugar de interacción, apropiación y reapropiación, que enlaza procesos reflejamente organizados y conocimiento experto sistemáticamente ordenado. El cuerpo mismo se ha emancipado, como condición para su reestructuración refleja. (...) El yo y el cuerpo, invadidos profundamente por los sistemas abstractos de la modernidad, se convierten en lugares de una diversidad de opciones nuevas de estilo de vida. (Giddens, 1997, pp. 271-291)

\section{Según datos registrados por The Economist:}

La industria global de la belleza corporal en 2003 activó flujos de 160 mil millones de dólares al año, con previsiones de crecimiento a futuro. (...) Las cifras estimativas del mercado mundial de las cirugías cosméticas (cirugías plásticas estéticas) y actividades relacionadas con el bienestar total (tratamientos integrales de belleza, ejercicio y dieta, asistencia a spas, clubes y centros especializados): es de alrededor de 20 mil millones de dólares por año (...) donde 11 mil millones son el consumo de cirugías plásticas esté- ticas en EEUU, país en el primer puesto del ranking mundial (Datos de la Sociedad Internacional de Cirugía Plástica (ISAPS). (Córdoba, 2010,p. 39)

Datos de las últimas décadas expresan que la población argentina da una importancia superlativa a la delgadez y la belleza, un artículo de The Wallstreet Journal publica:

Argentina en 2003 fue el quinto país del mundo en realizar procedimientos de cirugía estética siendo el $87 \%$ solicitados por mujeres (...) otro estudio demostró que las mujeres de Buenos Aires van al gimnasio con más frecuencia que los de cualquier otro país de América Latina (...)

y siendo que las exigencias en relación con un cuerpo ideal derivan frecuentemente en trastornos alimenticios "en una encuesta a 15.000 aspirantes universitarios de Argentina, en su mayoría mujeres, el 3,3\% dijo haber sufrido anorexia en algún momento". (Moffet TWJ, 2005) El aparato desplegado por el mundo de la imagenmercancía se ha vuelto parte del escenario del arte contemporáneo, las nuevas formas de arte ahora denominadas por Nicolás Bourriaud relacionales involucran a la obra dentro de los canales del consumo. De este modo,

Las autopistas de la comunicación, los medios electrónicos, los nuevos patrones sociales y simbólicos, las significaciones del mercado y valores derivados del comercio, entre otros serían los nuevos conceptos del juego de relaciones interactivas, sociales y relacionales que establecen los figurantes (consumidores) dentro del nuevo tablero de arte, inserto en las redes del consumo y del comercio. (Bourriaud, 2012)

No es por azar que el cuerpo sea uno de los temas centrales de exploración del arte relacional, donde artistas como Vanessa Beecroft, a través de sus eventos performáticos, realiza instalaciones con grupos de mujeres, desnudas, escasamente vestidas o en ropa interior, que exhiben sus cuerpos y actúan gestualmente portando tacos altos, durante períodos prolongados de tiempo, frente al estupor e incomodidad de los espectadores. Beecroft mediante sus "pinturas vivientes" (tableaux vivent según Dave Hickey) se instala sobre la representación del cuerpo femenino y los estereotipos culturales de Occidente, socavando las lecturas 
dominantes del lugar de la mujer en la sociedad y la cultura, el patriarcado, las nociones de género, la perfección física, la diferencia, la sexualidad, el feminismo, la pertenencia a una clase social, el fetichismo y la cosificación de la mujer promovida por la industria de la moda, entre otras (Steinmetz et al, 2006, pp. 1-37). Los conceptos explorados por Beecroft, encuentran relación con los definidos por Pierre Bourdieu y la correspondencia entre la espacialización del cuerpo dentro de una clase social (nociones de capital cultural, económico, social y simbólico), hábitus ("elemento generador de la práctica, como el factor primordial de la reproducción cultural o simbólica"), y "estilo de vida" (Bourdieu, 1988, p. 54 y ss, 124 y ss); Marcel Mauss y los usos (técnicas) del cuerpo instituidas por la cultura; centro de un escenario y el desarrollo de una conciencia corporal apropiada a los espacios públicos y otra para los privados basadas en un "orden moral" que indicarían como interactuamos en la presentación del yo en la vida diaria (Goffman, 1971, 1972 y 1979); la influencia de las cuestiones de género sobre la conciencia del cuerpo y su aspecto "las mujeres más que los hombres ven sus cuerpos como objetos a los cuales se ha de mirar" (Berger, 1972); la noción de Mary Douglas del cuerpo mediatizado por la cultura o entidad simbólica de comunicación física y social, donde el cuerpo se convierte en "símbolo" o vehículo de información del sistema social y sus presiones, dando cuenta de la relación entre el cuerpo y el contexto, expresando las preocupaciones del grupo de pertenencia. (Bourdieu, Mauss, Goffmann, Berger y Douglas, en Entwistle, 2002, pp. 18-50) Según Michel Maffesoli la cultura contemporánea está signada por la presencia de Dionisio (Baco), dios terrenal, del vino, de la naturaleza, figura emblemática definida como el más oriental de los dioses griegos. Bajo este modelo describe a la sociedad actual regida por el retorno a la naturaleza de origen femenina o la madre tierra, y sus atributos de sensorialidad, percepción y tribalidad como reflejo de la disolución de la identidad y su fusión en la tribu o viscosidad social. Este estado se traduce en cierto tipo de éxtasis social que se identifica por un excesivo culto al cuerpo, hedonismo, atención a la teatralidad obsesiva de los hechos de la vida, importancia suprema de la moda, adjudicación de valor predominante a la juventud, mixturización de los modos de creación y producción de la imagen, costumbres y tendencias, en un período espiritual de relativización de los supuestos (Maffesoli, 2001, pp. 165-192). La moda en este contexto, se ha transformado en un imperio económico marcario de orden mundial, una economía creativa cuya industria representa un $\$ 1.2$ trillón mundial, con más de $\$ 250$ mil millones gastados anualmente solamente en los circuitos de la moda de EEUU:

Donde la fabricación es sólo una fracción de la industria del vestido moderno ya que es una industria altamente sofisticada que implica la moda y estudios de mercado, la concesión de licencias de marca, los derechos de propiedad intelectual, el diseño, la ingeniería de materiales, fabricación de productos, la comercialización y finalmente, la distribución. (JEC, 2015)

Signado por la ansiedad epidémica de las tendencias y la programación de la obsolescencia de producto en un aceleramiento de los procesos productivos y de venta (fast fashion), se ha convertido en una de las políticas más agresivas desplegadas sobre la imagen del cuerpo, en la creación de una necesidad de ficción, cuyas reglas narcisistas y obsesivas (fashion victims) pueden llegar hasta la absurdidad, y dirigen en gran medida junto con la publicidad, la fabricación de la identidad social y la transformación en uno mismo (Erner, 2012, pp. 178203):

Un estimado de 900 empresas de moda tienen su sede en Nueva York siendo el mercado más grande del país, genera más de $\$ 15$ mil millones en ventas, es considerada la capital de la moda del mundo delante de París, Milán y Londres. (...) es el centro de las principales publicaciones de moda como Womens Wear Daily, Vogue y Harpers Bazaar, el hogar de algunas de las empresas de publicidad más grandes del mundo (...) medios 
sofisticados y recursos de marketing que los diseñadores pueden utilizar para promover sus productos y construir sus marcas (...) como Ann Taylor, Brooks Brothers, Calvin Klein, DKNY y Rocawear y resulta rentable no sólo en los ámbitos de la moda, sino en todas las industrias "ya que el 5\% de los diseñadores de moda norteamericanos trabajaron creando imagen durante 2013 en las industrias de cine y vídeo". (JEC, 2015)

El fast fashion consiste en el desarrollo de colecciones de bajo costo que imitan las últimas tendencias de las marcas de lujo, destinadas a saciar el deseo de compra de grandes masas de consumidores jóvenes del mundo industrializado. Resulta irónico que los compradores de fast fashion que siguen patrones de conducta alejadas de las ecológicas, frecuentemente comparten sin culpa ni contradicción una preocupación por los problemas ambientales. Algunos estudios creen que parte de la explicación, se basa en una falaz asociación del imaginario social que vincula la idea de sostenibilidad con el reciclaje y los productos orgánicos, y en el caso del mercado de la moda, con una asociación entre "imitación del lujo" y sostenible, cuestiones que lógicamente forman parte de los mensajes promovidos por las instituciones (Joy et al, 2012, pp. 273-296). El fast fashion en Europa:

Suele ganar márgenes de beneficio más altos, un 16\% que sus contrapartes tradicionales de distribución de moda, que promedió sólo el 7\% (Sull y Turconi, 2008 en Joy et al, 2013, pp. 273-296) un ejemplo es Inditex (Zara), que opera 2.700 tiendas en más de sesenta países, y está valorada en US \$24 mil millones, con ventas anuales de \$ 8mil millones (Crofton y Dopico 2006, p. 41 en Joy et al, 2012, pp. 273-296).

Curiosamente la exacerbación del consumo viene siendo la puerta al desencanto del consumidor frente al consumo sin sentido, en un camino de realineamiento y cuestionamientos tendientes a instalar conceptos de sostenibilidad y moda sostenible (Beard, 2008; Elsie, 2003 en Joy et al, 2013, pp. 273-296).

Algunas reflexiones sobre el cuerpo y el diseño en contextos de complejidad

Sin haber agotado ni descripto todos los enfoques que atraviesan al cuerpo en las décadas recientes, ni su vínculo inexorable con el vestido entendido como segunda piel en la cultura de Occidente, ni las implicancias del hipercapitalismo en relación con el cuerpo y el mercado; la emergencia del cuerpo es una constante que se hace presente en todos los aspectos de la vida de la sociedad contemporánea, cuya reconceptualización impacta sobre sí mismo como si se tratara de un territorio en puja, exploración, invasión y reconversión. La posmodernidad viene reescribiendo una iconografía y estética particular del cuerpo, transformativa, mediatizada y redistribuida ad infinitum por los simulacros en torno a la imagen-mercancía, a partir de las ideas del proyecto personal del cuerpo, cuyas imágenes impactan sobre las distintas variables de lo social, ficcional, performático y fashionable, y traducen la construcción de la identidad de lo individual y de lo colectivo. Las actividades que afectan directamente sobre la conceptualización actual del cuerpo en Occidente responden a las construcciones heredadas de la modernidad y requieren un espacio particular de reflexión que se pregunte sobre las distintas visiones de esa relación compleja y no siempre sostenible. Al respecto, el diseño en la sociedad posindustrial tiene nuevos capítulos inter-transdisciplinarios por resolver, que signan el presente y el futuro de la disciplina, y que están relacionados con evolucionar y desarrollar nuevos enfoques, el desafío de una sociedad más sostenible, y reevaluar la postura filosófica general de diseño. (Fuad Luke, 2004-2005) Históricamente el diseño y en particular de indumentaria han decodificado y creado sobre la relación que guardan los productos con el cuerpo, entendiendo que el cuerpo y el yo cobran identidad a partir de la adquisición y consumo del producto, visiones que representan al paradigma dominante y que hoy ha entrado en crisis. En el mismo sentido Findelli, expresa que el diseño fue llamado a la creación de productos industrialmente producidos (producción en serie) y 
culturalmente aceptables (creación de estilos de vida), y que se fue convirtiendo en la herramienta que le ha permitido a la industria reconducir y absorber sus impactos (Julier, 2000 y Findelli, 2001 en Fuad Luke, 20042005). La progresión del sistema hipercapitalista de las últimas tres décadas, ha llevado a una sofisticación y complejización de los productos y respuestas del diseño unido no solo a conceptos estéticos y ergonómicos, sino semióticos que dan curso a los variados estilos de vida que programan y reprograman las marcas y el mercado globalizado (ciclo de vida de los productos y programación de su obsolescencia), los que crean e instalan necesidades de vértigo, aceleración y exigencia a la vida del individuo en sociedad. Estos aspectos han cobrado una perspectiva particular en unión con el advenimiento y cruce que la tecnología digital ha tenido en todos los campos del conocimiento y en particular con el diseño. Según Kroker el hombre actual está situado en la unión de los pares materialidad-consumo y mecanicismo-automatismo, un estilo de vida sostenido por un capitalismo virtual (Kroker, 2006, en Di Bella, 2007, p. 42) que impacta directamente sobre sus criterios de identificación y la construcción del cuerpo social definiendo marcos de influencia fenomenológicos y ontológicos que afectan la experiencia humana y de su propio cuerpo. Movimientos recientes y no tanto, iniciaron un camino de búsquedas en relación con una nueva manera de entender la naturaleza, la sociedad y extensivamente a la economía, y se están orientando en la indagación de vertientes de pensamiento tendientes a la generación de esquemas de desaceleración de los procesos del hipercapitalismo. En el diseño los cuestionamientos están puestos en el seno de la disciplina, lo que ha iniciado un camino de controversias para el diseño tradicional, que entienden que es necesario reorientar la mirada del diseño hacia nuevas que retrasen la perspectiva del fast design hacia un slow design (Fuad Luke, 2004-2005). Algunas tendencias están retomando las búsquedas en un diseño orientado al ser humano que deponga las necesidades de productos basados únicamente en los parámetros del materialismo y el consumo retomando las ideas de un diseño universal, inclusivo, integral, para la diversidad (Mace et al, 1998- 2016), e interactivo y emocional (Norman, 2004) entre otras que se vinculan con la idea de experiencia y el bien común que instalan según Manzini "una ola de innovación social ha comenzado a poner en libertad cada vez más recursos sociales, tales como redes de personas activas y colaborativas, organizaciones por pares (to-peer organizaciones), y la difusión de conocimientos y habilidades". (Manzini, 2012, p. 1) Estas últimas entienden que en el mundo diseñado, se ven representados un conjunto de personas y no solo a una, superando para el diseñador el concepto de autoría que desplaza su función a la de facilitador (gatekeeper). Estos caminos y nuevas exploraciones descentran el lugar del diseñador y del diseño, posibilitando la interacción del público en las decisiones del diseño y extensivamente del mundo por intervenir, promoviendo modalidades de diseño participativo para el diseño de "su uso antes de su uso" y de un metadiseño o diseño del "diseño después del diseño". (Ehn, 2008, pp. 1-2)

La sostenibilidad es algo más que nuestra relación con el medio ambiente; se trata de nuestra relación con nosotros mismos, nuestras comunidades y nuestras instituciones. La sostenibilidad implica dinámicas ambientales complejas y cambiantes que afectan a la vida humana y el bienestar, con la intersección de dimensiones ecológicas, económicas y sociopolíticas, tanto a nivel mundial y como local. (Seidman, 2007, p. 58, en Joy et al, 2013, pp. 273-296)

Las implicancias de una sociedad más sostenible como garantía de supervivencia del planeta y de las futuras generaciones requieren de cambios socioculturales y tecnológicos significativos, que remitan a comportamientos en lo individual y en los negocios con beneficios medibles en términos de sostenibilidad, enfatizando el carácter social del diseño (Manzini, 1997; y Papanek, 1995 en Fuad Luke, 2004-2005) siendo que la actual cultura del 
diseño "sólo replica el status quo, en lugar de tratar de encontrar formas de diseño en evolución para satisfacer las necesidades y los desafíos contemporáneos". (Findelli 2001, en Fuad Luke, 2004-2005)

Desde la visión emergente y holística propuesta por el Diseño de Transición1, que se opone al avance del paradigma económico dominante acerca "del crecimiento desenfrenado y un imperativo de maximizar las ganancias" (Korten, 1999, 2010; Mander, 2012; Douthwaite, 1996 en Irwin et al, 2015, p. 1), Terry Irwin basada en los conceptos de Fritjof Capra, explica que la sociedad contemporánea y sus problemas más apremiantes derivan de una crisis de percepción "del hecho de que la mayoría de nosotros, y especialmente nuestras grandes instituciones sociales, siguen funcionando de acuerdo a los conceptos de una visión obsoleta del mundo" (Capra, 1982, pp. XVII-XVIII, en Irwin, 2012, p. 12). El paradigma de la visión de la sociedad occidental y que ahora está en crisis:

Consiste en una enquistada serie de ideas y valores, entre los que podemos citar la visión del universo como un sistema mecánico compuesto de piezas, la del cuerpo humano como una máquina, la de la vida en sociedad como una lucha competitiva por la existencia, la creencia en el progreso material ilimitado a través del crecimiento económico y tecnológico y, no menos importante, la convicción de que una sociedad en la que la mujer está por doquier sometida al hombre no hace sino seguir las leyes naturales. (Capra, 1998, pp. 27-28)

Terry Irwin reconoce que vivimos en "tiempos de transición" y "toma como premisa central la necesidad de transiciones sociales hacia un futuro más sostenible y la creencia de que el diseño tiene un papel clave que desempeñar en estas transiciones" esto implica que se hace necesario pensar en cómo conducir y afrontar cambios en todos los niveles de la sociedad que se hagan cargo de cómo daremos inicio a un camino de soluciones en torno a los grandes problemas contemporáneos como "el cambio climático, la pérdida de la biodiversidad, el agotamiento de los recursos naturales y la ampliación brecha entre ricos y pobres”, como para nombrar sólo algunos de los denominados "problemas perversos" o wicked problems que nos sitúan en el plano de sociedades en riesgo (Beck, 1992) y requieren nuevos enfoques de solución que potencien y desarrollen la capacidad de resiliencia del sistema (Manzini, 2012). Por esto apela a "que se hace necesaria una nueva forma de ver y pensar en los problemas hacia un nuevo paradigma de diseño basado en una visión holística del mundo". (Kearney, 1984; Woodhouse, 1996; Capra, 1983; Clark, 2002; Rozak, 2001 en Irwin, 2012, p. 12); y a que:

Las nuevas formas de diseñar tienen la necesidad de estar informadas del conocimiento que proviene del exterior del diseño: la ciencia, la filosofía, la psicología, las ciencias sociales, la antropología y las humanidades, etc." (...) "Esta concepción sistémica del problema es decir, su consideración como parte de un sistema complejo de elementos interdependientes y multiescala, requiere soluciones de diseño que no pueden concentrarse únicamente en la propia disciplina ni en una sola especialidad de diseño. (Irwin et al, 2015, pp. 1-2; Garcia i Mateu et al, 2015, pp. 1-10).

Entiende que es importante revisar "el conocimiento y la sabiduría del pasado para concebir soluciones en el presente atendiendo las necesidades de las futuras generaciones" e investigar "cómo se han desarrollado las grandes transiciones socio-técnicas y cómo se han manifestado a lo largo de la historia" (Geels, 2010; Griñán, Rotmans, Sc, 2010; Shove y Walker, 2007, en Irwin et al, 2015, p. 1) "para detectar el aprendizaje y la sabiduría de las sociedades indígenas pre-industriales que vivieron bajo conceptos sostenibles dando lugar a las nuevas generaciones" (Brown, 2013; Papanek, 1995; Whitt, 2001 en Irwin et al, 2015, p. 1); tiene la necesidad de una 
visión de un estilo de vida basado en lo local y lo regional que no desatienda la pertenencia a un espacio mundial "localismo cosmopolita" en lo que respecta la faz sensible y al intercambio de información y tecnología. (Manzini, 2009; Sachs, 1999, en Irwin et al, 2015, p. 1) Por último y para dejar esta discusión abierta, Meadows (1999) observa que la transformación de cualquier sistema debe partir de la base (marco de referencia o framework), desde el nivel de los paradigmas que son las fuentes de los sistemas. Findelli expresa que el paradigma actual de diseño, responde al marco de referencia que rige nuestros sistemas de creencias compartidas acerca de lo educativo, político, tecnológico, científico, jurídico y funcional de los sistemas sociales, y mientras este marco no se cuestione, explique o cambie, el paradigma seguirá siendo aceptado e indiscutible (Findelli, 2001, en Fuad Luke, 2004-2005). Por eso para vencer la resistencia al cambio cree importante indagar sobre las fallas que resultan persistentes y que pertenecen a los viejos paradigmas o los que han entrado en crisis, a partir de abrir el paso a las preguntas sobre las evidencias críticas de orden ambiental, económico y social que aquejan a nuestras sociedades, y de las que aún no hay respuestas concretas, ya que el verdadero desafío de la sostenibilidad consiste en apuntar a un cambio en los niveles más profundos y que tengan repercusión en el largo plazo.

Notas

1. La Universidad Carnegie Mellon y su School of Design ofrecen el Doctorado en Transition Design a cargo de Terry Irwin, Directora de la Escuela de Diseño, quién junto a Gideon Kossof y Cameron Tonkinwise investigan junto con su equipo, acerca del Diseño para la transición. El Diseño de transición es una práctica emergente dentro del ámbito del diseño que trabaja para crear estilos de vida alternativos beneficiosos para la economía, la sociedad y el planeta; es todavía es un ámbito en proceso de experimentación práctica e investigación crítica. Sitio del Programa de Diseño de Transición de la School of Design de la Universidad de Carnegy Mellon http://design.cmu.edu/content/program-framework. Sitio del Transition Design: http://www.transitiondesign.net 2. La Universidad de Palermo y la Facultad de Diseño y Comunicación han creado el Programa Diseño en Perspectiva que participa reflexivamente con las ideas del Diseño de Transición y lo ha incorporado dentro de los temas de análisis, en la currícula de la Maestría en Gestión del Diseño. Sitio del Programa Diseño en Perspectiva: http://www.palermo.edu/dyc/programa_inves tigacion/diseno_perspectiva.html

3. Este artículo se denomina El cuerpo como territorio, siendo este el título con el que la autora de este artículo denominó a una performance audiovisual de arte conceptual (actualmente en curso), que trata sobre la inevitabilidad del territorio corporal.

Referencias bibliográficas

Baudrillard, J. (2009). La sociedad de consumo. Sus mitos, sus estructuras. España: Siglo XXI Editores. Beck, U. (1992). La sociedad de riesgo. Cambridge: Polity Press. Belting, H. (2007). Antropología de la imagen. Buenos Aires: Katz Editores. Bourdieu, P. (1988). La distinción. Criterios y bases sociales del gusto. España: Taurus. Bourriaud, N. (2207). Estética relacional. Buenos Aires: Adriana Hidalgo Editora. Capra, F. (1998). La trama de la vida. Una nueva perspectiva de los sistemas vivos. Barcelona: Editorial Anagrama. Córdoba, M. (2010). Las cirugías estéticas como práctica social distintiva: un lacerante encuentro entre corporeidad e imaginario social. Revista Latinoamericana de Estudios sobre Cuerpos, Emociones y Sociedad №2. Año 2. Argentina: Unidad Ejecutora CEA-CONICET (UNC). www.relaces.com.ar Di Bella, D. (2007). Arte tecnomedial: Programa curricular. En: Cuadernos del Centro de Estudios en Diseño y Comunicación. Ensayos Nº 25 (2008). pp. 39-75. Buenos 
Aires: Facultad de Diseño y Comunicación. Universidad de Palermo. Di Bella, D. (2013). Aspectos inquietantes de la era de la subjetividad: lo deseable y lo posible. En: Cuadernos del Centro de Estudios de Diseño y Comunicación N43. Acerca de la subjetividad contemporánea: evidencias y reflexiones. Año XIII, Vol43, pp. 127-139. Buenos Aires: Facultad de Diseño y Comunicación. Universidad de Palermo. Di Bella, D. (2015). Ex Obra, la rematerialización de la imagen en movimiento. Disponible en: www.elojosalvaje.com ISSN 2362-4227. Ehn, P. (2008). Participation in design things. En: Proceedings of the 10th Anniversary. Conference on Participatory Design. New York: ACM. pp 94-98. Entwistle, J. (2002). El cuerpo y la moda. Una visión sociológica. Barcelona: Paidós, Contextos. Erner, G. (2012). Víctimas de la moda. Cómo se crea, porqué la seguimos. Barcelona: Editorial Gustavo Gili. Esteban, M. L. (2004). Antropología del cuerpo. Género, itinerarios corporales, identidad y cambio. Barcelona: Ediciones Bellaterra. Foucault, M. (1980). La microfísica del poder. Madrid: La Piqueta. Foucault, M. (1996). Las tecnologías del yo y otros textos afines. Barcelona: Paidos. Foucault, M. (2000). Vigilar y castigar. Madrid: Siglo XXI. Foos, C. (2012). Lo que el tatuaje escribe en el cuerpo. El tatuaje como signo: Conferencia pronunciada el espacio de Conferencias Introductorias al Psicoanálisis del NUCEP-Madrid el 10-10-2011. Madrid. En: Revista Letras, №4 2012. Fuad Luke, A. (2004-2005). Slow theory. A paradigm for living sustainably? Disponible en: http://www.slowdesign.org/pdf/Slow\%20design.pdf

Garcia i Mateu, A. \& Costa, T. (2015). Transition Design: Investigación y diseño colaborativo para procesos de emancipación ciudadanos. España: Universidad Autónoma de Barcelona: Grupo de Investigación Design Processes: Innovative Practices in Art \& Design del EINA, Centro Universitario de diseño y arte adscrito a la Universidad Autónoma de Barcelona; y Grupo de Investigación Generating Knowledge in Artistic Research: Towards an Alternative Account. A Meeting Point of Philosophy, Art and Design. Departamento de Estética, Facultad de Filosofía. Giddens, A. (1997). Modernidad e identidad del yo. El yo y la sociedad en la época contemporánea. Barcelona: Ediciones Península. Serie Historia, Ciencia y Sociedad. Gimlin, D. (2000). Cosmetic Surgery: Beauty as Commodity. En: Qualitative Sociology, Vol 23. №1. EEUU: Human Sciences Press, Inc. Gimlin, D. (2006). El proyecto del cuerpo ausente: La cirugía estética como una respuesta a la Dis-Apariencia. Sociology. Vol 40:4. pp. 699-716. Irwin, T. (2012). Wicked Problems and the Relationship Triad. En Grow Small, Think Beautiful: Ideas for a Sustainable World. Schumacher College: Floris Books. Irwin, T.; Kossoff, G.; Tonkinwise, C. \& Scupelli, P. (2015). Transition Design 2015. A new area of design research, practice and study that proposes design-led societal transition toward more sustainable futures. Pittsburg, EEUU: Carnegie Mellon University. School of Design. JEC (Joint Economic Committee, United State Congress, EEUU) (2015). The Economic Impact of the Fashion Industry. Disponible en: http://www.jec.senate.gov/public/_cache/ files/2523ae10-9f05-4b8a-8954-631192dcd77f/jec-fashion-industry-report----sept- 2015-update.pdf Joy, A.; Sherry, J. Jr.; Venkatesh, A.; Wang, J. \& Chan, R. (2012). Fast Fashion, Sustainability, and the Ethical Appeal of Luxury Brands. En: Fashion Theory, Vol.16, Issue 3, pp. 273-296. Le Breton, D. (2002). Antropología del cuerpo y modernidad. Buenos Aires: Ediciones Nueva Visión. Mace, R.; Story, M. \& Mueller, J. (1998). The Universal Design File: Designing for People of All Ages and Abilities. EEUU: Center for Universal Design, NC State University. En: Mace Universal Design Institute. Disponible en: http://udinstitute.org/universal.php Maffesoli, M. (2001). El instante eterno. El retorno de lo trágico en las sociedades posmodernas. Buenos Aires: Editorial Paidós. Marks, L. (2000). The Skin of the Film: Intercultural Cinema, Embodiment, and the Senses. Durham: Duke UP. Manzini, E. (2012). Resilient Systems and Cosmopolitan Localism - The Emerging Scenarios of the Small, Local, Open and Connected Space. CNS Ecologia Politica. Available online: http://www.ecologiapolitica.org/wordpress/wp-content/uploads/2014/03/Resilientsystems-and-cosmopolitanlocalism.pdf. Meadows, D. H. (1999). Leverage Points: Places to intervene in a system. The Sustainability 
Institute. Available at: http://www.sustainabilityinstitute.org/pubs/Leverage_Points.pdf Merleau-Ponty, M. (1985). Fenomenología de la percepción. Barcelona: Planeta. Moffet, M. (2005). In Argentine Province, Fashion Police Say Small Isn't Beautiful Striking Blow for Body Image, Law Seeks Larger Sizes; Eating Yourself Out of Style. EEUU: The Wall Street Journal. Staff Reporter. Disponible en: http://www.wsj.com/articles/SB113297108 $944107177 ? \mathrm{cb}=$ logged $0.36534600681625307 \& \mathrm{cb}=$ logged0.6191034766379744

Norman, D. (2004). Diseño emocional. Nueva York: Basic Books. Papanek, V. (1995). The Green Imperative. Ecology and Ethics in Design and Architecture. UK: Thames \& Hudson. Peeters, H. \& Charlier, P. (1999). Introduction. Contribution à une théorie du dispositif. En: Le Dispositif: Entre usage et concept. Hermès, París. Ritzer, G. (1996). La macdonalización de la sociedad. Un análisis de la racionalización en la vida cotidiana. Barcelona: Editorial Ariel. Salzman, A. (2004). El cuerpo diseñado. Buenos Aires: Editorial Paidós. Steinmetz, J.; Cassils, H. \& Leary, C. (2006). Behind enemy lines: Toxic titties infiltrate. Vanessa Beecroft. En Signs: Journal of Women in Culture and Society. Vol 31. º3. EEUU: Universidad de Chicago. Zizek, S. (2006). Órganos sin cuerpo. Sobre Deleuze y sus consecuencias. Valencia: Editorial Pre-Textos.

\section{Abstract:}

The body, in contemporary society, is a space for reconceptualization. Postmodernism is rewriting an iconography and a particular body aesthetic around the "commodity-image". This new image impacts the different categories of the social, fictional, performative, and fashionable, which in turn alters the construction of the individual's and the collective's identities. The design of clothing in particular has created a new relationship between apparel and the body. It is now necessary to reflect on the different visions of this relationship that has not always been a sustainable relationship. The post-industrial design society has new challenges to solve through interdisciplinary engagement; these mark the present and the future of design processes, teaching, and design practices.

Key words:

body - image - new conceptualization - pos modernism - iconography - aesthetics - identity - complexity sustainable - interdiscipline.

\section{Resumo:}

Assistimos a uma emergência do corpo na sociedade contemporânea que pode assumir-se como um espaço de reconceituação. A post modernidade vem re-escrevendo uma iconografia e estética particulares do corpo em relação à imagem-mercancia, que impacta nas diferentes variáveis do social, ficcional, performático e fashionable, que traduzem a construção da identidade do individual e do coletivo. O design e em particular de indumentária decodificaram e criaram sobre a relação entre produtos e corpos. É necessário também refletir sobre as visões dessa relação complexa e não sempre sustentável. O design na sociedade pó-industrial tem novos capítulos interdisciplinares por resolver, que selam o presente e o futuro da disciplina.

\section{Palavras chave:}

corpo - imagem - reconceituação - pós-modernidade - iconografia - esté- tica - identidade - complexidade sustentável - inter-disciplina. 
El cuerpo como territorio fue publicado de la página 137 a página152 en Cuadernos del Centro de Estudios de Diseño y Comunicación № 64 